Revue internationale P.M.E.

Économie et gestion de la petite et moyenne entreprise

Revue

internationale

PME

\title{
Les modes de management des entreprises au Maroc : entre contingences culturelles et économiques
}

\section{Nadia Benabdeljlil}

Volume 20, numéro 2, 2007

URI : https://id.erudit.org/iderudit/1008518ar

DOI : https://doi.org/10.7202/1008518ar

Aller au sommaire du numéro

Éditeur(s)

Presses de l’Université du Québec

ISSN

0776-5436 (imprimé)

1918-9699 (numérique)

Découvrir la revue

Citer cette note

Benabdeljlil, N. (2007). Les modes de management des entreprises au Maroc : entre contingences culturelles et économiques. Revue internationale P.M.E., 20(2), 89-122. https://doi.org/10.7202/1008518ar

\section{Résumé de l'article}

Cet article analyse l’influence de la culture sociétale sur les relations hiérarchiques et les attitudes managériales dans les entreprises marocaines. Après une revue de la littérature qui a conduit à une première sélection de valeurs et attitudes culturelles pertinentes relativement au contexte marocain une enquête exploratoire et qualitative a été menée auprès d'un échantillon de responsables hiérarchiques dans des entreprises industrielles au Maroc.

Les résultats révèlent qu'une entrée par la culture est utile mais insuffisante pour comprendre les spécificités des attitudes au travail et des relations sociales dans l'entreprise. D'autres variables contextuelles explicatives et notamment celles qui conditionnent le degré de précarité des situations de travail dans les PME marocaines sont mises en évidence.

L'article montre en outre comment des leviers culturels sont mobilisés par les managers au Maroc, permettant à certains d'asseoir leur pouvoir et à d'autres de surmonter les obstacles eux aussi d'origine culturelle.
Ce document est protégé par la loi sur le droit d'auteur. L'utilisation des services d’Érudit (y compris la reproduction) est assujettie à sa politique d'utilisation que vous pouvez consulter en ligne.

https://apropos.erudit.org/fr/usagers/politique-dutilisation/ 


\section{Notes de recherche}

\section{Les modes de management des entreprises au Maroc: entre contingences culturelles et économiques}

Nadia BENABDELJLIL

École Mohammadia d'Ingénieurs Université Mohamed V-Agdal

MOTS CLÉS

Pratiques managériales - Culture sociétale

Entreprises marocaines - Attitudes au travail - Valeurs culturelles Représentations culturelles - Hiérarchie - Pouvoir - Paternalisme

\section{L'AUTEURE}

NADIA BENABDELJLIL détient un doctorat en sciences de gestion et elle est professeure au Département de génie industriel de l'École Mohammadia d'Ingénieurs (EMI), Université Mohammed V, Rabat.

Ses travaux de recherche récents portent notamment sur la gestion du changement, en relation, par exemple, avec les démarches de certification à la qualité ou les impératifs de modernisation des entreprises marocaines. Adresse: École Mohammadia d'Ingénieurs, Université Mohamed V - Agdal, avenue Ibn Sina, B.P. 765, Rabat, Maroc. Courriel : <nadiab@ emi.ac.ma>.

\section{RÉSUMÉ}

Cet article analyse l'influence de la culture sociétale sur les relations hiérarchiques et les attitudes managériales dans les entreprises marocaines. Après une revue de la littérature qui a conduit à une première sélection de valeurs et attitudes culturelles pertinentes relativement au contexte marocain, une enquête exploratoire et qualitative a été menée auprès d'un échantillon de responsables hiérarchiques dans des entreprises industrielles au Maroc. 
Les résultats révèlent qu'une entrée par la culture est utile mais insuffisante pour comprendre les spécificités des attitudes au travail et des relations sociales dans l'entreprise. D'autres variables contextuelles explicatives et notamment celles qui conditionnent le degré de précarité des situations de travail dans les PME marocaines sont mises en évidence.

L'article montre en outre comment des leviers culturels sont mobilisés par les managers au Maroc, permettant à certains d'asseoir leur pouvoir et à d'autres de surmonter les obstacles eux aussi d'origine culturelle.

\begin{abstract}
This article analyses the impact of the culture in society, on hierarchical and managerial attitudes in middle and small Moroccan enterprises. First, we started by an epitome of the literature which leads us to a first selection of relevant values and attitudes to Moroccan context. Then a qualitative investigation was undertaken with a panel of managers (hierarchical responsables) in charge of industrial enterprises in Morocco.

The result of this study shows that culture is a useful way of understanding the management situation in a company. However, it remains inadequate to have a full understanding of the reality of the staff's attitude at work and social relations in a firm. Other contextual variables are needed, among them, those about the level of lack of job security are highlighted.
\end{abstract}

This article shows also how cultural considerations are activated by the management in Morocco, allowing to a few of them to assume power, and to others, to behave in a way to overcome obstacles from cultural origins.

\title{
RESUMEN
}

Este artículo analiza la influencia de la cultura en la sociedad, sobre las relaciones jerárquicas y las actitudes de gestión en las empresas marroquíes. Después de pasar revista a la literatura que ha llevado a una primera selección de los valores y actitudes culturales pertinentes relativos al contexto marroquí, una encuesta exploratoria y cualitativa ha sido llevada a cabo sobre una muestra de responsables jerárquicos en las empresas industriales en Marruecos.

Los resultados demuestran que la cultura permite entender en parte la situación de la gestión en la empresa. No obstante, resulta inadecuada para entender plenamente la realidad de las actitudes en el trabajo y de las relaciones sociales. Otras variables contextuales explicativas, y particularmente aquellas que condicionan el grado de precariedad de las situaciones laborales en la pequeña y mediana empresa marroquí, resultan evidentes.

El artículo demuestra por otro lado, cómo los incentivos culturales son movilizados por los empresarios en Marruecos, permitiendo a algunos asentar su poder, pero a otros también, actuar de manera que se sobrepasen los obstáculos, ellos mismos de origen cultural. 


\section{ZUSAMMENFASSUNG}

Dieser Artikel analysiert den Einfluss der gesellschaftlichen Kultur auf die hierarchischen Beziehungen und die Einstellungen der Manager in marokkanischen Unternehmen. Nach Durchsicht der Literatur, die zu einer ersten Auswahl einschlägiger Werte und Einstellungen der marokkanischen Kultur geführt hat, wurde eine exploratorische, qualitative Untersuchung anhand einer Stichprobe von Verantwortlichen in Industrieunternehmen in Marokko durchgeführt.

Die Ergebnisse zeigen, dass die Kultur nützlich, aber ungenügend ist, um die Besonderheiten der Einstellungen zur Arbeit und zu den sozialen Beziehungen im Unternehmen zu begreifen. Andere kontextuelle, erklärende Variablen, insbesondere jene, die den Grad der Unsicherheit der Arbeitssituation in den marokkanischen KMU beeinflussen, können nachgewiesen werden.

Der Artikel zeigt ausserdem auf, wie einige Manager in Marokko kulturelle Elemente einsetzen um ihre Macht zu festigen oder andere versuchen, ihre eigenen kulturellen Einstellungen zu lockern.

\section{Introduction}

Le courant dit du «management interculturel»s'intéresse à l'impact des cultures locales sur les organisations et leur mode de management, en se basant en particulier sur des comparaisons internationales. Des chercheurs (Hofstede, 1980; d'Iribarne, 1989) ont ainsi pu montrer que des entreprises comparables, notamment sur le plan de la taille, de la technologie ou de la nationalité, fonctionnaient selon des systèmes culturels différents selon le pays d'accueil. Au sein de ce courant cependant, une controverse porte sur la place réelle à accorder aux cultures nationales comme dimension explicative des comportements managériaux.

Pour les tenants du culturalisme, c'est dans la culture que réside l'explication essentielle des différences observées aussi bien au plan macro- (niveaux de développement des pays), que microéconomique (pratiques organisationnelles notamment). On peut cependant relever deux limites à leurs travaux: d'une part, ils n'apportent pas d'indications théoriques, ni méthodologiques, permettant de comprendre les mécanismes selon lesquels la culture serait à l'origine de ces différences (Lachman, Nedd et Hinings, 1994). D'autre part, il semble que d'autres facteurs potentiellement explicatifs soient ignorés par les approches culturalistes, comme des facteurs d'ordre économique (pour des pays du tiers-monde, par exemple, le niveau de vie ou la pauvreté), ou encore politique ou institutionnel.

Pour ceux qui s'opposent à ces conceptions culturalistes du développement et du comportement, les différences observées s'expliquent, non par la culture, mais par des dimensions comme l'environnement économique ou les impératifs de la technologie (Hickson, Hinings et Schwitter, 1974; Hickson et al., 1979) ${ }^{1}$.

1. Cités dans Lachman, Nedd et Hinings, 1994, p. 45.

Revue internationale P.M.E., vol. 20, nº 2, 2007 
Dans cette recherche, qui a pour but de participer à l'éclaircissement des rapports sociaux et des attitudes au travail dans les entreprises marocaines, nous adopterons une position intermédiaire, à savoir que la dimension culturelle est susceptible d'expliquer seulement une partie des comportements : la culture nationale «ne représente qu'une partie de la réalité. L'autre partie relève de la matérialité des situations, des ressources, des contraintes, des opportunités et des capacités que les contextes immédiats d'action fournissent aux acteurs »; on ne peut tout ramener à une culture nationale, au risque de lui conférer un «poids exorbitant dans l'analyse des conduites » (Friedberg, 2005, p. 183).

Pour cerner l'objet de notre recherche, nous avons adopté le paradigme selon lequel «dans l'entreprise, ni les capacités des acteurs, ni leurs identités ne peuvent être disjointes de leurs rapports à la société » (Maurice, 1992, p. 318), et notamment à l'environnement socioculturel et économique. Nous avons essayé de caractériser cette «matérialité des situations» de travail à travers une enquête qualitative, dont nous restituons ici une partie des résultats.

La question de l'intégration de la culture sociétale dans et par le management est un point d'entrée de cette enquête, mais pas le seul. D'un côté, nous nous sommes interrogée sur le rôle des facteurs culturels dans les modes de management de l'entreprise (rapports hiérarchiques, régulation du pouvoir au sein de l'entreprise, attitudes au travail, etc.). Au Maroc, la culture représente-t-elle un levier d'action pour le management? Au niveau des acteurs, dans quelle mesure influence-t-elle les comportements et les possibilités de réponse à des situations données? La gestion qualifiée de «traditionnelle », de «paternaliste ${ }^{2} »$, serait-elle une fatalité pour une majorité d'entreprises marocaines? De l'autre, nous avons été attentive aux autres dimensions susceptibles d'influencer les comportements des acteurs, comme celles relatives au dirigeant (personnalité et formation, cultures individuelles), au secteur d'activité (cultures sectorielles) ou encore à la technologie utilisée dans l'organisation.

Après une revue de la littérature qui permettra d'asseoir le cadre conceptuel de cette recherche et d'en préciser les axes d'investigation (1), nous présenterons l'enquête réalisée et la méthodologie de traitement des données adoptée (2), puis en rapporterons les principaux résultats (3 et 4).

2. Caractéristique mise en évidence, par exemple, par des enquêtes dont rendent compte El Aoufi (2000) ou Mezouar (2002). 


\section{Cadre conceptuel}

Les études qui portent sur les relations entre culture et management ou organisation peuvent être classées en trois types (Tisserand, 2001):

- celles qui cherchent à décrire les groupes professionnels à partir de leur culture, considérée comme un ensemble de pratiques professionnelles partagées; on parle alors de culture de métier ou de culture d'entreprise. Les travaux de Schein (1984) ou de Sainsaulieu (1992) vont dans ce sens;

- celles qui visent à établir des particularités nationales à partir d'approches comparatives entre pays: la culture y est considérée soit comme une variable que l'on cherche à modéliser à partir d'enquêtes auprès d'employés d'entreprises (Hofstede, 1980; Trompenaars et HampdenTurner,1993), soit comme une variable indépendante dont on cherche l'influence sur les comportements au travail (d'Iribarne, 1989);

- celles, enfin, qui se penchent sur des cas de rencontres entre cultures différentes et sur les relations intergroupes qui en découlent (cas des fusions d'entreprises, des travailleurs immigrés, etc.).

Notre travail se situe plutôt dans le deuxième type d'approches bien qu'il ne s'agisse pas d'une démarche comparative et que notre propos ne soit pas de réduire la culture à une identité nationale uniquement: il s'agit de préciser les liens entre culture et comportements managériaux, en questionnant un contexte donné dans le cadre d'un postulat général, à savoir que les comportements sont influencés par plusieurs types de variables, dont des variables culturelles. Ce sont ces variables et leur combinaison complexe que nous nous proposons ici d'analyser, dans le cas d'entreprises marocaines.

La question étant toutefois de savoir comment déterminer concrètement, dans ce cas, ce qui relève de la culture, nous commencerons par revenir sur le concept pour en préciser les fondements, puis analyserons les résultats d'études sur les relations entre culture et management au Maroc.

\subsection{La culture sociétale, ensemble de représentations et contexte de sens}

La notion de culture sociétale peut être caractérisée par plusieurs aspects (Loth, 2006 p. 30): elle est acquise et non pas innée; elle a forcément une dimension collective, celle d'un groupe humain organisé; elle est évolutive, pour permettre à l'homme de s'adapter; elle génère des significations (valeurs, normes, comportements) partagées; enfin, elle a une dimension pragmatique : elle sert à résoudre les problèmes qui se posent aux groupes humains. 
Au sens anthropologique du terme, la culture sociétale peut être considérée soit comme un construit, soit selon un sens «socioperceptif», comme une représentation (Tisserand, 2001).

La culture comme construit se traduit par des productions d'ordre matériel (outils, techniques, œuvres d'art, etc.), ou sociologique (éléments partagés par les membres d'un même groupe sur le plan comportemental: rites, codes sociaux, organisation de la société, etc.). Elle a aussi un aspect dynamique, celui du processus de socialisation, c'est-à-dire du mécanisme de l'intégration d'un individu à un groupe particulier par l'intériorisation des valeurs et normes culturelles propres à ce dernier, notamment par le biais de l'éducation (Dayan, 1999, p. 112).

La culture est aussi considérée comme représentation, au sens où elle influence les perceptions et la manière de considérer les choses; à ce titre, les anthropologues la considèrent comme «un ensemble [...] d'interprétations que les membres d'une société donnent de leur expérience, de constructions qu'ils édifient par-dessus les événements qu'ils vivent» (Geertz, 1992, p. 105). La culture devient alors, pour les individus, un contexte dans lequel l'action prend sens (d'Iribarne, 2005; Friedberg, 2005).

Le concept reste toutefois difficile à appréhender, voire à caractériser concrètement dans un contexte donné: en effet, la culture s'articule autour de certaines constantes, sans pour autant être immuable (Cuche, 2004). Elle est en perpétuelle évolution et peut être considérée comme un processus de transformations, d'intégrations et de rejets, qui n'est pas sans contradictions et conflits (Zghal, 1994).

Par ailleurs, la culture sociétale au sein d'un même groupe n'est pas unique et homogène, mais plurielle, ce qui est peut-être d'autant plus vrai pour un pays comme le Maroc «qui a acquis l'art de faire tenir ensemble des choses complètement disparates» (Geertz, 1992, p. 91). On peut alors considérer qu' «une culture sociale est beaucoup plus une procédure d'articulation de différences qu'elle n'est le partage sans problèmes de valeurs et représentations communes» (Serres et Lévi-Strauss ${ }^{3}$ ).

Étudier une culture dans la perspective d'en cerner une éventuelle implication sur des attitudes managériales pose, dans un premier temps, la question du choix et de la définition des dimensions qui la caractérisent. Cette question porte finalement, à un niveau plus large, sur la possibilité «d'opérationaliser» le concept de culture sociétale.

3. Cités dans Sainsaulieu, 1987, p. 222.

Revue internationale P.M.E., vol. 20, nº 2, 2007 


\subsection{Une "opérationalisation » du concept de culture?}

Différents auteurs ont proposé des modèles visant à caractériser concrètement une culture dans un contexte donné.

Schein (1984) définit la culture comme la manière dont un groupe social résout ses problèmes et distingue trois niveaux dans la culture organisationnelle:

- les artefacts, qui peuvent être observés et constituent les éléments les plus apparents de la culture (comportements, rites, produits, etc.);

- les valeurs, moins perceptibles, qui pourront être cernées à travers des questionnaires ou des entretiens;

- les croyances ou hypothèses, invisibles et qui nécessiteront des méthodes d'investigation cliniques ou ethnographiques pour être mises en évidence.

Pour un auteur comme Hofstede (1980,2001), les valeurs constituent le corps d'une culture. À partir d'une enquête quantitative étendue aux filiales d'une même multinationale dans 64 pays, il synthétise cinq dimensions qui contribuent à définir une «identité culturelle» à un plan national. Bien que sa démarche méthodologique et son modèle se soient heurtés à des critiques ${ }^{4}$, ces dimensions peuvent aider à analyser des comportements culturels, notamment au sein des entreprises. Elles sont les suivantes:

- le degré de «distance hiérarchique» dans les relations (manière dont le pouvoir est exercé, attentes et comportements des subordonnés par rapport à l'exercice de l'autorité);

- la dimension «individualiste» ou «collectiviste» du comportement (manière dont sont envisagées les relations entre l'individu et le groupe);

4. Les critiques portent sur la vision statique de la culture impliquée par son modèle et sur le fait que la culture n'est appréhendée que dans sa dimension «valeurs», sans prendre en compte les processus ou les interprétations. Sur le plan méthodologique ont été soulignés: les limites d'une enquête quantitative pour appréhender des aspects culturels, l'insuffisance d'un seul cas d'entreprise (le cas prénommé «Hermès») pour une approche comparative entre les cultures, le fait que cinq dimensions sont insuffisantes pour étudier une culture (Eckhardt, 2002). Au-delà de son modèle, les explications de type culturaliste apportées par Hofstede aux événements historiques, politiques, économiques et sociaux sont controversées. Enfin, Hofstede (2001) reconnaît lui-même le biais méthodologique (interprétation selon un modèle culturel occidental) dont son modèle peut souffrir, et appelle d'ailleurs à en relativiser les conclusions. 
- le degré de tolérance envers l'incertitude (ou degré d'inquiétude provoqué par des événements futurs incertains);

- l'indice de «masculinité» ou de «féminité» d'une société (division sociale des rôles entre l'homme et la femme dans la société, valeurs dominantes comme l'affirmation de soi ou l'attention accordée aux autres);

- la perception du temps (valeurs associées à une orientation à court terme ou à long terme).

Selon Hofstede, les dimensions culturelles relevées influenceraient, au niveau des entreprises, des aspects comme les critères de recrutement (selon les compétences, en fonction de l'appartenance à un groupe...), les outils de motivation mis en œuvre (par des aspects matériels et/ou par les relations humaines...), ou encore le degré de formalisation des contrats de travail. D'autres auteurs montrent que les valeurs culturelles influencent, au sein des entreprises, des éléments comme le style de décision, l'action stratégique, l'innovation, la créativité, l'engagement, la satisfaction au travail (Ali et Wahabi, 1995), ou encore le choix, par un groupe social donné, à la fois des objectifs et des moyens particuliers selon lesquels ces objectifs seront atteints (Lachman, Nedd et Hinings, 1994; Friedberg, 2005).

Trompenaars et Hampden-Turner (1993), reprenant la définition de la culture de Schein, l'appréhende à travers trois dimensions ${ }^{5}$, proches de celles développées par l'anthropologue américain Hall (1984):

- les relations avec les autres (existence de règles universelles ou particulières s'appliquant à certains cas; orientation vers l'individu ou le groupe; relations sociales neutres ou qui tiennent compte des sentiments; degré d'implication personnelle dans la relation; caractère attribué ou acquis du statut social);

- l'attitude à l'égard du temps (programmé avec précision ou non);

- les relations entretenues avec l'environnement et l'espace (usage fait de l'espace, volonté de contrôle de la nature).

Pour d'Iribarne (1989), enfin, la culture renvoie à un ensemble de processus d'interprétations; il adopte une approche basée sur des études de cas qualitatives et approfondies pour analyser la manière dont la culture

5. Il mesure toutefois chaque dimension à partir de questions proposant des choix binaires qui peuvent paraître trop simples pour cerner la dimension dans sa complexité. 
affecte les façons de travailler ensemble ${ }^{6}$ et dégage des valeurs culturelles à un plan national, induisant des attitudes particulières à l'égard du travail: par exemple, sens de l'honneur et culture de la dignité (en France), logique de la contractualisation des rapports de travail (aux États-Unis), logique du consensus (aux Pays-Bas).

$\mathrm{Au}$ vu de ces travaux, il nous semble que les analyses portant sur les relations entre culture sociétale et management ou comportements au sein de l'entreprise, portent sur trois niveaux.

1) Le niveau des valeurs, sociales ou individuelles, parmi lesquelles sont évoquées dans les recherches la dignité au travail, la loyauté, le degré de confiance dans les individus et entre les groupes, la recherche du consensus, la solidarité.

2) Le niveau des attitudes (personnelles et relationnelles) ou des comportements, qui se traduisent par des éléments comme la considération de l'autorité (obéissance, respect du statut, de la compétence...); les formes que prennent les relations hiérarchiques (relations centrées plutôt sur le travail ou les individus: degré de «professionnalisation » ou d'affectivité dans la relation); la tolérance envers l'incertitude ou le risque (programmation du temps, projection dans le futur); l'importance respective accordée à l'individu et au groupe, induisant notamment des comportements individualistes ou solidaires; les modes privilégiés de communication (en face à face, par le biais d'un intermédiaire), de gestion des conflits (affrontement ouvert, évitement, etc.). On trouve aussi dans ces attitudes des compétences comme l'esprit d'initiative ou la créativité.

3) Le niveau des représentations: représentations relatives à l'entreprise, à la technologie, au produit; au pouvoir et à ses sources de légitimation; au temps et à l'espace; représentations relatives au travail: Lachman, Nedd et Hinings (1994) par exemple, distinguent deux tendances opposées, à savoir la perception du travail comme un moyen d'atteindre des objectifs non liés au travail et un statut social (orientation instrumentale), ou comme une activité de haute valeur en soi (orientation expressive).

6. La lecture que d'Iribarne fait des cas analysés est également critiquée par certains (Bourrier, 2005; Friedberg, 2005), au sens où, par exemple, il ne fait pas référence aux institutions des pays concernés (rôle de l'État, du système éducatif, etc.), et que des biais méthodologiques (interprétations personnelles au chercheur) peuvent être présents. 
Cette distinction en trois niveaux a guidé l'élaboration du questionnaire que nous présentons plus loin. Ces niveaux ne sont toutefois pas indépendants les uns des autres: une valeur peut se traduire par des comportements ou par des représentations et il peut être difficile de «classer» de manière systématique une manifestation de type culturel dans une rubrique donnée. Par exemple, l'obéissance ou la soumission peut être une attitude culturelle, mais aussi une valeur lorsqu'elle est prônée par des systèmes d'éducation (l'obéissance aux anciens, par exemple). D'autre part, des comportements a priori culturels, comme des manifestations de solidarité, peuvent être plus ou moins encouragés par des facteurs contingents à l'environnement social et économique. C'est pourquoi, à notre avis, toute tentative de compréhension d'une culture sociétale, dans une perspective de mise en relation avec des pratiques de management, ne peut être dissociée de la prise en compte des contextes économiques et sociaux concernés.

\subsection{Une culture managériale proprement marocaine?}

Les observateurs de la culture marocaine s'entendent sur sa diversification et son hétérogénéité, aussi bien sur les plans ethnique, linguistique que culturel. La société marocaine est décrite comme étant construite de "pièces d'identité nationale» $\left(\right.$ Benjelloun $\left.{ }^{7}\right)$ plutôt que d'une seule identité; de «morceaux, d'organes de société de types différents» $\left(\operatorname{Pascon}^{8}, 1980\right)$. Elle est dépeinte avec des termes variés: «démontrer ce qu'il y a de patriarcal, tribal, féodal, industriel, prospectif, etc. dans le comportement de l'homme marocain, c'est en fait reconnaître la nature même de sa société» (Pascon' ${ }^{9}$ 1980). L'hétérogénéité de la société est également structurelle, par les niveaux et la division des classes sociales.

À travers une enquête élargie ${ }^{10}$ auprès d'entreprises marocaines, Ali et Wahabi (1995) ont cherché à caractériser les systèmes de valeurs des managers marocains et à analyser dans quelle mesure les valeurs culturelles influencent leurs comportements. Leurs résultats révèlent que la diversité de la société marocaine se reflète, dans une certaine mesure, dans les atti-

7. Cité dans Larcher, 2003.

8. Cité dans El Amrani et Chebihi, 2003, p. 9.

9. Idem.

10. Leur questionnaire a été soumis à 600 entreprises à Casablanca, Rabat, Marrakech et Mohammadia, avec un taux de retour de $39 \%$. Les entreprises de l'échantillon relèvent du secteur public et du secteur privé et sont de grande taille puisque environ $60 \%$ emploient plus de 750 employés. Leur enquête se base en partie sur un questionnaire développé par Flowers et al. (1975), lui-même basé sur un modèle d'analyse des valeurs construit par Graves (1970), selon six systèmes de valeurs. 
tudes des managers, au sens où ces derniers relèvent de systèmes de valeurs variés, auxquels l'appartenance est fonction des dimensions suivantes: le revenu, le pays de formation, la région d'origine, le niveau hiérarchique, l'âge, l'ancienneté, la classe sociale, le travail du père.

Ali et Wahabi (1995) distinguent finalement quatre profils types de managers au Maroc: le manager centré sur son propre intérêt et sur le profit à court terme, plutôt autoritaire et peu regardant des sentiments des autres; le manager «manipulateur», qui a réussi grâce à son réseau de relations et/ou à des manœuvres politiques et qui, d'abord matérialiste, recherche le gain et le pouvoir; le manager «citoyen » et ouvert sur l'environnement qui développe un climat de travail agréable, partage les bénéfices de l'entreprise avec les employés; le manager de type «tribal», qui centralise la prise de décision et s'entoure de la famille pour la gestion de son affaire. Le profil dominant serait toutefois celui du manager centré sur son propre intérêt.

Comparant cette tendance avec celles des managers dans les autres pays arabes de manière globale, les auteurs concluent que les dimensions politiques et économiques de l'environnement influencent davantage les comportements des managers marocains que les facteurs culturels.

D'autres d'études sur les entreprises marocaines ramènent le débat sur la culture et font état de tendances au niveau des comportements au travail et des relations hiérarchiques. Par exemple, El Amrani et Chebihi1 ${ }^{11}$ (2003) observent que le mode de management au Maroc se distingue, globalement, par une grande distance hiérarchique, une domination de valeurs «masculines» au sens défini par Hofstede, une logique de l'opportunisme, du court terme et de la rente. Ils identifient, par ailleurs, au sein des entreprises, des valeurs de solidarité et d'attachement à la famille et à l'ethnie. Certaines de ces dimensions sont confirmées par d'autres études (El Aoufi et al., 2000) qui montrent que, de manière générale, l'entreprise marocaine est caractérisée par un système de relations de travail fondées sur le paternalisme ${ }^{12}$, la dépendance, voire le clientélisme.

11. À la suite d'une enquête dans 87 entreprises publiques et privées, relevant de différents secteurs et réparties sur l'ensemble du territoire marocain, pour laquelle ils ont utilisé en partie le questionnaire de Hofstede.

12. Pour Zghal (1994, p. 180), le paternalisme, selon lequel «la relation employeurserviteur se définit en termes de père-fils plutôt que maître-serviteur », est «à la fois une attente des travailleurs et une donnée affectant les structures organisationnelles». Les employés attendent que leurs intérêts, même en dehors du travail, soient pris en charge par leurs responsables hiérarchiques. Cela conduit à accorder une place importante à l'affectivité dans les relations, au détriment d'une définition objective des droits et des devoirs de chaque partie, et au développement de «situations floues». 
Le comportement des employés marocains, quant à eux, est décrit en termes contrastés: d'un côté, pour Al Jabari ${ }^{13}$ (1990) par exemple, ils seraient soumis et peu portés à initier du changement; comme causes à cette attitude, on peut distinguer d'après ses explications une régulation sociale liée au mode de pouvoir dominant, au sens où l'élite traditionnelle (politique, religieuse, économique) prêchait la loyauté et l'obéissance; et une cause liée à l'éducation, dans le sens où l'obéissance aux anciens est valorisée dans les familles.

D’un autre côté, des enquêtes auprès de salariés marocains ont révélé que la notion de travail est associée, à leurs yeux, à des valeurs de type culturel et symbolique qui subliment le travail (logique de l'honneur, moyen «d'être digne » et de gagner «le pain des enfants»), auxquelles s'ajoute une considération économique assimilant le travail salarié à un moyen d'intégration sociale (moyen de vivre et protection contre la pauvreté; El Aoufi et al., 2000).

Ces résultats, qui mettent l'accent sur des tendances culturelles dominantes au sein des entreprises au Maroc, ont participé au choix des dimensions à retenir au niveau de notre questionnaire: comme valeurs évoquées dans ces travaux, on trouve celles de la dignité dans le travail, de la solidarité interpersonnelle. Parmi les attitudes, il y a celles de l'obéissance, du respect de la hiérarchie et du statut, en conséquence, d'un esprit d'initiative plutôt peu développé; d'une «affectivité» dans les relations hiérarchiques se traduisant par du paternalisme. Parmi les représentations figurent celles du travail comme voie d'accès à la dignité et à l'intégration sociale.

L'objectif de l'enquête que nous présentons maintenant était justement de cerner dans quelle mesure ces dimensions sont intégrées dans (ou si elles ont un impact sur) les modes de management et dans quelle mesure des variables autres que culturelles sont à prendre en considération dans l'explication des configurations sociales au sein des entreprises marocaines.

\section{Méthodologie de la recherche}

Tenter d'appréhender des relations entre culture et management, que ce soit au Maroc ou ailleurs, se heurte à une double difficulté, d'ordre conceptuel et méthodologique.

\subsection{Difficultés et précautions méthodologiques}

Sur le plan conceptuel, d'abord, on peut relever que de multiples définitions sont apportées au concept de culture. De plus, une culture n'est pas mesu-

13. Cité dans Ali et Wahabi, 1995.

Revue internationale P.M.E., vol. 20, nº 2, 2007 
rable comme l'est le niveau de développement économique et les cultures ne peuvent être comparées entre elles à partir d'échelles indicielles; elle n'est que difficilement dissociable d'autres facteurs explicatifs. Par voie de conséquence, sur le plan épistémologique, la difficulté est de savoir comment rendre compte d'une culture sans la trahir et sans tomber dans «l'illusion positiviste des sciences sociales» (Cuche, 2004, p. 112).

Sur le plan méthodologique, ensuite, l'étude de la culture souffre du «caractère insaisissable de son objet ${ }^{14}$ »; la principale question serait de reconnaître dans un contexte donné ce qui relève du culturel, d'une part, et d'arriver à le qualifier, de l'autre. Friedberg (2005, p. 185) rappelle à cet égard que la question de «la manière de trouver cette culture nationale» est «non encore résolue: ou bien on s'en donne une définition a priori, à partir d'études historiques, d'enquêtes d'attitudes ou avec toute autre méthode; ou bien elle est reconstruite à partir des régularités de comportement relevées dans des espaces d'action contrastés et diversifiés: il ne peut alors s'agir que d'une construction hypothétique et provisoire, qui doit prendre garde au raisonnement circulaire qui trouve les régularités dont elle a fait l'hypothèse en gommant [...] des irrégularités peut-être tout aussi significatives ».

Par exemple, lors de deux monographies dont l'objectif était d'analyser les rôles respectifs de la culture sociétale tunisienne et de la structure sur les comportements organisationnels, Zghal (1994) conclut finalement à la difficulté d'isoler le facteur culturel: «l'enquête a montré qu'une telle hypothèse est irréaliste car la culture pénètre la structure: d'une part, elle imprègne la philosophie managériale des décideurs et, d'autre part, ces derniers sont amenés à ajuster leur comportement aux réactions de leurs subordonnés culturellement déterminés ».

Pour le chercheur qui vise à cerner une culture, il s'agit finalement de «découvrir [...] les cadres permettant de considérer des matériaux au premier abord disparates de telle façon que cette disparité elle-même nous conduise à les comprendre plus profondément» (Geertz, 1992, p. 69), car les outils classiques dont nous disposons sont controversés: entre des enquêtes quantitatives comme celles adoptées par Hofstede (1980) ou Trompenaars et Hampden-Turner (1993), visant à modéliser des variables ou attitudes culturelles nationales à travers des questions proposant une série de choix préétablis aux répondants et des études de cas qualitatives telles que celles pratiquées par d'Iribarne (1989), quelle voie méthodologique choisir?

14. Pour reprendre une expression de Geertz (1992, p. 15) à propos de l'étude des religions. 
$\mathrm{Au}$ vu de ces questionnements, une approche de type constructiviste paraissait la plus adaptée à la problématique traitée: il s'agit, à travers des situations observées, de (re)définir l'objet étudié en le structurant. Dans le cadre de cette approche, deux choix ont été faits.

D'une part, celui de nous baser non pas sur nos propres observations, celles-ci pouvant elles-mêmes être sujettes à des représentations culturelles personnelles et, à ce titre, représenter un biais méthodologique, mais de cerner l'incidence de la culture à travers l'analyse des perceptions ${ }^{15}$ de responsables hiérarchiques, dans des entreprises marocaines ou installées au Maroc, sur les relations, les valeurs et attitudes au travail des employés qu'ils ont à gérer. Il s'agit donc d'analyser dans quelle mesure la culture sociétale, appréhendée à travers la perception de valeurs ou attitudes culturelles par les responsables hiérarchiques au Maroc, influence la configuration des relations de travail et la mise en ouvre de pratiques managériales.

D'autre part, celui de privilégier une méthode d'enquête qualitative, basée sur des entretiens approfondis destinés à recueillir et à analyser des discours de managers, dont le vocabulaire, étant lui-même porteur de culture et de sens, est un point de départ essentiel pour une analyse culturelle (Abraham, 1992).

\subsection{Les thèmes de l'enquête}

Les dimensions culturelles en relation avec le management relevées dans la littérature ne pouvaient toutes, pour des raisons de faisabilité, être abordées lors d'entretiens de face à face. Le processus de sélection de ces dimensions, qui devaient représenter autant d'axes du questionnaire, a été mené à la lumière de travaux analogues effectués sur les entreprises marocaines et cités ci-dessus, puis d'entretiens avec quatre praticiens (deux dirigeants et deux consultants) sur les particularités des attitudes et des relations de travail au Maroc et, enfin, de notre propre connaissance de ces dernières (Benabdeljlil, $\left.2004,2000^{16}\right)$.

Finalement, à part celles relatives aux données objectives concernant l'entreprise et l'interlocuteur, les questions se répartissent en trois volets principaux ${ }^{17}$.

15. La perception ou représentation «renvoie à l'existence d'une interface de nature cognitive entre la façon dont l'homme perçoit le monde et le monde tel qu'il est» (Lesca et Bartel-Radic, 2001). Il s'agit en fait pour nous d'identifier non des représentations individuelles, mais sociales, c'est-à-dire "partagées par les membres d'un groupe social», en l'occurrence, celui des managers.

16. Cité dans El Aoufi et al., 2000.

17. Les entretiens portaient aussi sur d'autres questions dont les résultats ne sont pas abordés ici. 
1. Perception par la hiérarchie des valeurs chez la main-d'œuvre: le sens de la discipline, le sens du devoir, le sens de la solidarité et le respect de la hiérarchie ont été les dimensions retenues à cet effet.

2. Perception des attitudes et des compétences individuelles dans l'entreprise, et notamment: la capacité de la main-d'œuvre à prendre des initiatives, à se soumettre aux contraintes de rendement et de qualité, qui sont apparus comme étant des préoccupations centrales dans les propos des quatre praticiens préalablement interviewés.

3. Représentations en relations avec les pratiques managériales et notamment la possibilité de faire confiance ${ }^{18}$ et la mise en œuvre de pratiques de délégation ou de contrôle, les représentations du pouvoir et de la relation hiérarchique (à travers des discours et pratiques traduisant un degré de «professionnalisme» ou au contraire des aspects affectifs dans les rapports avec les employés).

$\mathrm{Au}$ sein des entreprises, ces trois volets devraient être liés entre eux ainsi: les valeurs et attitudes culturelles des employés au sein des entreprises seraient influencées à la fois par la culture sociétale et par d'autres facteurs qu'il s'agit de mettre en évidence. Elles influenceraient elles-mêmes les comportements et pratiques managériales des responsables hiérarchiques, ce qui peut être illustré selon le schéma suivant.

\section{FiguRE 1}

\section{Les liens entre les dimensions retenues dans le questionnaire}

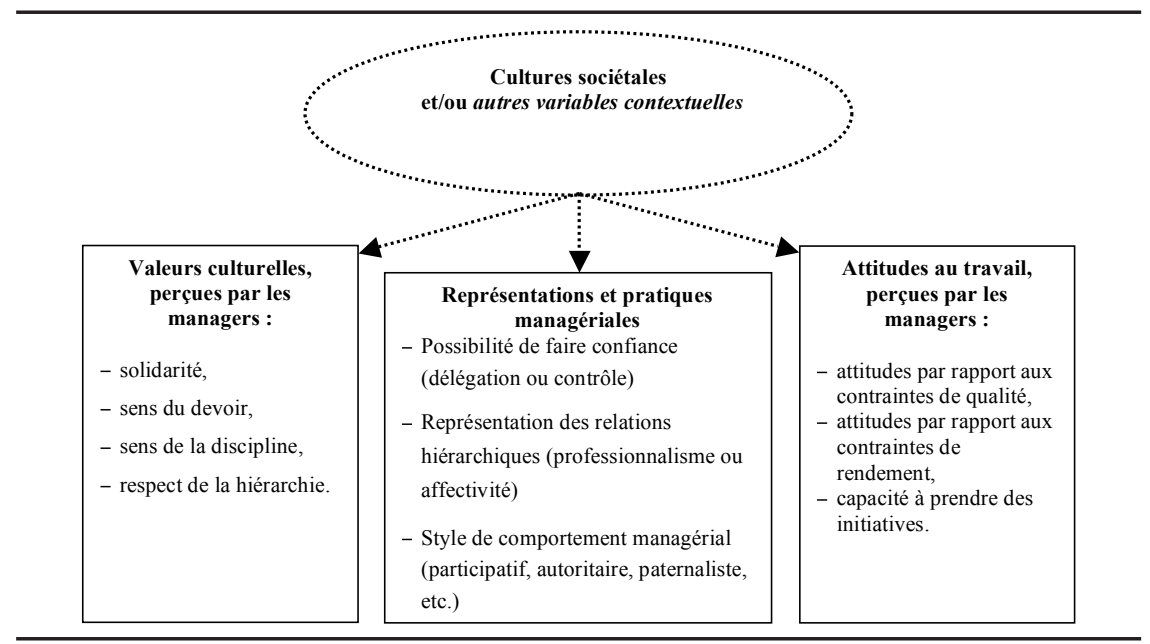

18 L'hypothèse étant que celle-ci devrait être elle-même induite par les perceptions concernant trois des valeurs précédentes (sens du devoir, sens de la discipline, respect de la hiérarchie) et donc être, pour un répondant donné, en cohérence avec elles.

Revue internationale P.M.E., vol. 20, nº 2, 2007 


\subsection{Une analyse de discours}

Le «monde social» retenu pour l'enquête est celui du système de production dans lequel, a priori, les contraintes de rendement se traduisent par des enjeux de performance et d'incitation, par des relations de pouvoir, elles-mêmes potentiellement empreintes de culture. L'enquête a pris la forme d'entretiens approfondis en face à face qui se sont déroulés au sein des entreprises avec des acteurs relevant de trois niveaux hiérarchiques: directeurs généraux, responsables de production et agents de maîtrise.

Il s'agissait toutefois de ne surtout pas «gommer les irrégularités...» (Friedberg, 2005), et nous avons cherché dans les discours aussi bien les points communs que les points antinomiques autour desquels ils s'articulaient. De ce fait, l'échantillon requis pour cette analyse ne devait pas nécessairement rechercher une représentativité statistique, qui aurait requis un échantillon beaucoup plus étendu, mais la significativité, en s'efforçant de choisir les cas les plus diversifiés possibles par rapport au thème traité (Michelat, 1975).

La composition finale de l'échantillon a été guidée par cet objectif de diversifier, autant que possible, les entreprises, en termes d'abord de secteurs d'activité, de technologie ou de mode de production utilisé et, dans une moindre mesure, de taille, de nationalité, ou de régions afin de prendre en compte des sous-cultures éventuellement.

Cinquante-quatre entretiens approfondis ont été réalisés dans 35 entreprises, dont 25 à capital social entièrement marocain, 4 entreprises à pourcentage étranger minoritaire dans le capital, 4 filiales de multinationales et 2 PME étrangères. Ces six dernières entreprises ont été volontairement retenues dans l'objectif d'interviewer aussi des cadres de nationalité étrangère: nous avons pensé que leur expérience à l'international favoriserait une perspective comparative avec d'autres pays (et notamment leur pays d'appartenance) et partant, une «prise de recul» à la fois sur les questions relatives aux particularités des comportements au travail au Maroc et aux jeux des relations humaines, ce qui s'est en effet vérifié lors des entretiens.

Parmi les 35 entreprises, 3 sont de grande taille (effectif supérieur à 1000 personnes), les autres sont des PME; 11 sont des sociétés anonymes (SA), 23 des sociétés à responsabilité limitée (SARL) et il y a un atelier artisanal. Elles sont localisées dans trois zones économiques et géographiques et relèvent de secteurs ventilés comme suit: textile-confection (14 entreprises, la plupart exportatrices ou sous-traitantes, effectif moyen 297); industries métallurgiques et mécaniques (4 entreprises, effectif moyen 116); industrie agroalimentaire ( 3 entreprises dont une très grande, effectif moyen 20 , hors la très grande); ameublement (2 grandes entreprises); électroménager 
(2 entreprises); chimie-parachimie (2 entreprises, effectif moyen 70); imprimerie ( 2 entreprises, effectif moyen 24); travaux de chantier (2 entreprises, effectif moyen 78); BTP (une entreprise, effectif 200); autres (plasturgie, cristal, bijouterie): 3 entreprises.

Dans ces entreprises ont été interviewés 15 dirigeants (dont deux d'entreprises étrangères, et deux DG français de filiales de multinationales), 22 responsables de production (dont deux de nationalité française, dans les filiales de multinationales) et 17 agents de maîtrise.

S'agissant à la fois de cerner des tendances et de recueillir des discours, le choix a été fait de combiner questions fermées et questions ouvertes: le questionnaire comprend ainsi 22 questions ${ }^{19}$ fermées à échelle de Likert à quatre niveaux, sollicitant les opinions et représentations des interlocuteurs, toutes suivies de questions ouvertes de relance et d'approfondissement.

Le traitement des discours a été réalisé en deux étapes: une première a consisté à identifier les thèmes autour desquels les discours s'articulaient pour chaque axe du questionnaire, et à les classer selon l'occurrence de leur apparition afin d'identifier éventuellement des représentations dominantes, mais aussi marginales. Une seconde étape a mis en relation, par le recours à des «méta-matrices non ordonnées» (Miles et Huberman, 1991), ces représentations avec les caractéristiques de l'interlocuteur (âge, type de formation, fonction) et de l'entreprise (secteur, marché et technologie notamment). Le croisement des occurrences dans les discours avec ces dimensions a permis de mettre en évidence des régularités culturelles, mais aussi des facteurs de différenciation, liés aux contextes ou à la personnalité des répondants.

Nous présentons ces résultats dans les deux points suivants, en montrant d'abord quelle est la relation entre les situations de travail et la représentation des valeurs culturelles (point 3 ), et comment ces dernières influencent ellesmêmes les comportements au travail et les pratiques managériales (point 4). Du traitement des discours ressortent des variables autres que culturelles, qui influencent elles aussi les représentations.

\section{Situations de travail et représentations des valeurs culturelles}

Dans les entreprises analysées, le regard porté par l'encadrement sur la main-d'œuvre devrait effectivement refléter une culture de la «base» perçue par l'encadrement, mais aussi des attentes de ce dernier puisqu'une opinion donnée devrait être formulée en fonction d'un référentiel implicite. Ce

19. Dont 17 ont été traitées pour cet article.

Revue internationale P.M.E., vol. 20, nº 2, 2007 
référentiel pourrait être relatif à une culture sociétale influençant ces attentes (les managers baignant eux-mêmes dans un contexte culturel), à des cultures ou contraintes sectorielles, ou, enfin, à des attitudes ou cultures individuelles de managers.

Le traitement des discours recueillis sur ces thèmes essaie donc de prendre en considération ces deux dimensions (représentations et attentes), par rapport à des valeurs qui ont été dans le questionnaire déclinées en quatre types: sens de la discipline, respect envers la hiérarchie, sens du devoir au travail et solidarité entre ouvriers.

\subsection{La discipline, stratégie rationnelle de la main-d'œuvre face à un rapport de force déséquilibré}

Plus de $70 \%$ des responsables interviewés pensent qu'il y a un sens de la discipline chez la main-d'œuvre (dont $40 \%$ de «tout à fait»). Ceux qui l'estiment négativement relèvent pour la plupart du secteur de la confection ${ }^{20}$.

Les commentaires obtenus sur la question de la discipline indiquent que celle-ci est d'abord comprise comme le respect de règles formelles de présence et non comme le respect de procédures de travail, par exemple, révélant l'aspect généralement «scolaire» du contrôle hiérarchique. Par conséquent, les problèmes de discipline évoqués, quand ils existent, sont essentiellement relatifs à de l'absentéisme, les discours mettant l'accent sur des facteurs contextuels ${ }^{21}$ expliquant les absences ou retards. Certaines entreprises font d'ailleurs de cette discipline attendue le principal critère de sélection de la main-d'œuvre à l'embauche.

Par rapport à cette perception, des attitudes managériales majoritaires (a) et marginales $(b)$ ont pu être mises en évidence.

a) Le sens de la discipline est perçu par la plupart des répondants non pas comme une valeur intrinsèque aux ouvriers, mais par le fait que cela fait partie des règles du jeu et que les ouvriers n'ont pas le choix, les propos les plus significatifs à cet égard se retrouvant dans les entreprises de confection. La situation structurelle de crise dans

20. Notons toutefois que, dans la même entreprise, les avis peuvent diverger; dans une entreprise de confection, par exemple, le responsable d'atelier porte un jugement très sévère sur le sens de la discipline, tandis que le dirigeant est plus positif, ce qui peut indiquer une dimension plus individuelle qu'organisationnelle de la perception.

21. Problèmes de transport, difficulté de faire garder les enfants pendant les heures de travail, pour une main-d'œuvre essentiellement féminine comme c'est le cas dans le secteur de la confection. 
le marché de l'emploi est plus particulièrement exploitée par les entreprises relevant de ce secteur, dans lesquelles le rapport de force et le contrôle de type taylorien qui s'ensuit est le plus apparent: «il est obligé (d'être discipliné) non parce qu'il est éduqué, mais parce qu'il sait qu'il sera renvoyé» déclare, par exemple, un responsable de production.

Inversement, cette situation de crise économique devient un atout pour certaines entreprises comme les filiales de multinationales visitées, dont les responsables sont conscients que la comparaison implicite que fait la main-d'œuvre avec le contexte de l'emploi prévalent engendre un comportement rationnel de «discipline» et d'investissement dans le travail: «il n'y a aucun problème mais il y a ici des conditions de travail exceptionnelles : les ouvriers reçoivent six fois le SMIG (local). Avec les conditions d'hygiène, de sécurité... les gens sont bien ici». Un DG français souligne ainsi le « dévouement» des ouvriers, «qui viennent travailler le samedi matin sans être payés en heures supplémentaires, ce qui n'existe pas en France».

b) Dans quelques entreprises, cependant, la discipline se met plutôt en place soit à l'issue de négociations tacites, soit à travers «l'exemple» montré par le «chef», qui cherche à développer un esprit de groupe et une culture organisationnelle interne. Ces démarches, plutôt isolées dans notre échantillon, sont d'abord le fait de personnalités de responsables hiérarchiques (davantage que de l'entreprise dans son ensemble ou du secteur d'appartenance), qui mettent en œuvre des pratiques de dialogue et de proximité. Confiance, rigueur et respect sont les mots qui reviennent dans leurs propos.

Finalement, les perceptions des responsables interviewés quant à la discipline de la main-d'œuvre au travail montrent que celle-ci, telle qu'elle est comprise dans la majorité des cas (ponctualité et assiduité), est plus contingente aux situations de travail qu'elle n'est une valeur culturelle immuable. Par ailleurs, des personnalités isolées aboutissent à la mise en œuvre d'autres méthodes de régulation ${ }^{22}$ que celles basées sur un style de commandement autoritaire.

22. Même dans les entreprises de l'échantillon relevant du secteur de la confection, où deux cas de dirigeants «leaders» ont été rencontrés. 


\subsection{Le respect envers les supérieurs: entre rationalité contingente et soumission de type culturel}

De manière générale, les responsables interrogés s'accordent sur le fait que les ouvriers leur témoignent du respect et qu'ils n'ont pas de difficulté à se faire obéir, mis à part quelques cas isolés qui relèvent tous du secteur de la confection. Leurs discours révèlent cependant que le respect n'est pas tellement lié à une reconnaissance du statut ou d'une compétence, mais se situe entre une rationalité contingente de l'ouvrier $(a)$, et une soumission de type culturel à l'autorité $(b)$.

a) Pour une majorité de responsables, le respect que leur témoigne la main-d'œuvre est associé aux termes de «crainte», de «peur» ou encore de «soumission». Il s'agit de la peur d'être sanctionné ou de perdre son poste, qui est exploitée comme un moyen de contrôler la main-d'œuvre, certains recourant pour ce faire à des références plus ou moins explicites aux conditions défavorables de l'environnement économique et, notamment, à la menace de la perte de l'emploi; d'autres en profitant pour asseoir leur autorité, rappelant le rapport de force dans lequel ils l'inscrivent («Il gagne un salaire donc il doit se soumettre», dit ainsi un responsable de production).

Du côté des managers, cette attitude, qui est la plus fréquemment rencontrée, semble traduire une perception culturelle de ce que sont les rapports hiérarchiques.

Concernant la main-d'œuvre, le sentiment de crainte éprouvé à l'égard de la hiérarchie n'est pas uniformément répandu et s'avère inversement proportionnel à deux aspects principaux. D'une part, un niveau plus élevé de formation de l'ouvrier, qui rend la relation hiérarchique plus centrée sur le travail que sur les relations. D'autre part, des conditions de travail correctes et une attitude de respect envers les employés, qui sont évoquées par certains comme facteurs contribuant à une mise en confiance de la main-d'œuvre et à davantage d'investissement dans le travail. Ainsi, pour cette gérante d'une petite entreprise de confection, «on a instauré le respect. [...] elles savent qu'on est en famille. Il n'y a pas de harcèlement moral ou d'insultes envers les ouvriers comme ça se pratique dans d'autres entreprises». Pour le directeur d'une imprimerie, l'ouvrier «se sent avec sa famille, respecté, pas de corvée, pas d'exploitation et donc en cas de cadence du travail personne ne dit non».

b) Par ailleurs, la culture sociétale marocaine est mobilisée (inconsciemment dans la majorité des cas) par le management dans les entre- 
prises analysées, au sens où elle est porteuse de valeurs de respect de la hiérarchie et de l'autorité. Certains des responsables interrogés évoquent explicitement cet aspect: «La mentalité marocaine fait du chef une personne toujours valorisée », déclare, par exemple, un agent de maîtrise dans la confection.

Si elle permet à une majorité de responsables de jouer sur un registre autoritaire, elle devient un levier positif pour quelques-uns, qui essaient de dépasser cette soumission et s'appuient plutôt sur le potentiel d'adhésion, voire de dévouement, qu'ils y perçoivent. C'est ce que traduit, par exemple, un directeur général dans la métallurgie: «Il y a beaucoup de soumission, qu'il faut combattre tout en essayant d'en tirer les avantages. Les gens sont dévoués corps et âme au départ. Il y a là un très grand potentiel. Mais cela peut évoluer vers des relations biaisées de clientélisme.»

Le facteur discriminant de ce comportement qui recherche la mobilisation plutôt que la contrainte paraît être d'abord celui de personnalités ou de cultures individuelles ${ }^{23}$, puisque dans des situations d'entreprises comparables, on trouve des attitudes managériales divergentes.

Quant à l'attitude d'autoritarisme, elle se trouve confrontée, pour les entreprises analysées, à ses propres limites : lorsque la main-d'œuvre n'est pas ou ne peut être mise en confiance, lorsque son adhésion n'est pas recherchée se développent des comportements rationnels orientés d'abord vers la sauvegarde légitime de l'emploi, combinaisons de manifestations d'obéissance, voire de passivité (qui sont interprétées comme des attitudes culturelles et finalement critiquées par les managers), mais aussi de comportements cachés de résistance face aux pressions induites par le rendement.

\subsection{Le sens du devoir, contingent aux situations de travail}

Pour les responsables interviewés, le sens du devoir a été compris comme le degré d'investissement dans le travail, dans le sens d'un travail «bien fait». Les perceptions concernant cet aspect sont assez variées et deux groupes peuvent être distingués: sens du devoir perçu négativement et expliqué par le faible niveau de formation de la main-d'œuvre, ou encore révélateur de

23. Et non celui du niveau de formation ou de l'âge, puisque à niveau d'âge et de formation (diplôme étranger, par exemple) équivalents chez des différents dirigeants, on trouve des attitudes relativement opposées. Nous n'avons pu toutefois approfondir, dans le cadre de cette enquête, l'aspect «culture personnelle » (familiale?) de la personne. 
démotivation par rapport à un travail peu valorisant $(a)$; sens du devoir perçu positivement (par un peu plus de la moitié des répondants) et stimulé grâce au système de management mis en place $(b)$.

a) Pour un peu moins de la moitié des répondants, le sens du devoir est perçu plutôt négativement: «30\% ont une conscience professionnelle, $70 \%$ en ont moins », pense le DG d'une PME de confection. Cette perception justifie un contrôle direct sur le travail et se traduit fréquemment dans des propos du type: «Il faut toujours être derrière.» «Il y a peu d'investissement dans le travail. Ils [les ouvriers] ont besoin de suivi et de surveillance, comme des gamins.»

Si ces attitudes sont expliquées en partie par le «niveau intellectuel et le niveau de formation» (gérante d'une PME de confection) de la main-d'œuvre, ce sont aussi les facteurs travail et technologie, avec notamment la pression du rendement, qui semblent induire dans certains cas des comportements de résistance des ouvriers ${ }^{24}$ et, par voie de conséquence, une perception négative du «sens du devoir» par l'encadrement. Cela justifie alors, pour certains, le recours à davantage de contrôle et au développement d'un système de management taylorien.

b) Une perception positive ou plutôt positive du sens du devoir au travail par les responsables hiérarchiques paraît encourager chez ces derniers ${ }^{25}$ le recours à des attitudes de proximité à l'égard de la maind'œuvre. Ils insistent en effet sur la responsabilité de l'encadrement, ou encore sur le rôle d'une «culture maison» en ce qui concerne le comportement de la main-d'œuvre au travail. D'autres encore mettent en avant des stimulants d'ordre culturel; c'est notamment le cas des dirigeants des quatre entreprises de l'échantillon situées en dehors de zones industrielles ou de grosses agglomérations et qui associent dans leur discours ce sens du devoir à des sous-cultures régionales qui seraient porteuses de sens de l'honneur, de dignité, de valorisation du caractère sacré du travail, en les opposant à une mentalité «polluée» de grandes villes ${ }^{26}$. Ces dirigeants jouent sur

24. «L'ouvrier résiste, il dit toujours: "Je dépends de celui de devant"», commente par exemple un dirigeant dans la confection.

25. Pas chez tous toutefois, puisque l'on trouve aussi dans ce groupe une minorité de responsables exprimant une attitude managériale basée davantage sur l'incitation au travail par le contrôle et la contrainte que par la mobilisation et l'adhésion.

26. Et notamment à Casablanca, ville dans laquelle la main-d'œuvre est décrite par certains responsables comme étant «endurcie», par opposition à une maind'œuvre plus rurale perçue comme étant encore «pure », «digne» (termes utilisés par les interviewés). 
ce levier «sens de l'honneur» pour mobiliser le personnel par des attitudes de valorisation ${ }^{27}$, s'adaptant dans ce sens à un environnement culturel perçu.

Sur cet aspect, le comportement de la main-d'œuvre dans les entreprises observées est finalement à la fois contingent à des situations locales de travail et culturellement influencé. En effet, même dans des cultures régionales perçues comme porteuses de sens du devoir ou de «travail bien fait », celui-ci ne s'exprimera, à long terme tout au moins, que si les conditions de mise en confiance et de valorisation de la main-d'œuvre sont réunies, mettant ainsi en évidence une influence réciproque entre culture et management et la responsabilité de ce dernier par rapport aux comportements dans le travail.

\subsection{Le sens de la solidarité entre ouvriers, levier pour le management}

Les relations entre les ouvriers marocains dans le cadre du travail se caractérisent par une grande solidarité, sur laquelle s'accordent tous les responsables interviewés et pour laquelle les explications avancées sont d'abord d'ordre culturel.

Certains cadres ressentent une tradition de solidarité sociale, «familiale et tribale» (dirigeant dans l'agroalimentaire) qui se perpétue au sein de l'entreprise et se manifeste par des aides matérielles entre ouvriers qui vivent une situation difficile, mais aussi par un partage du travail en cas d'absence de l'un d'eux. Elle est perçue par certains comme un levier pour la motivation, au sens où l'esprit de groupe est finalement spontané et exploité comme un atout par ces derniers. «En France, c'était chacun pour soi; ici, il y a beaucoup de chaleur humaine», commente cette responsable hiérarchique qui avait eu une expérience de travail à l'étranger. D'autre part, les conditions de vie en général difficiles de la main-d'œuvre ainsi que la déficience, dans la majorité des cas, d'un système de couverture sociale encouragent et structurent les solidarités («ils se serrent les coudes», constate ainsi cette responsable dans le BTP).

Finalement, l'analyse des discours sur la perception des valeurs culturelles retenues dans notre questionnaire et relevées dans d'autres travaux

27. Comme exemple de comportements relevés, on peut noter chez deux dirigeants de «petites» PME et deux agents de maîtrise dans de grandes entreprises, le fait de rendre visite aux employés chez eux, à l'occasion des fêtes religieuses, ou encore lors d'arrêts pour maladie. Un dirigeant déclare par exemple: «Il faut un style humain et avant tout humain. Les Marocains sont modelés dans la même pâte. Il faut juste savoir quel type d'ingrédient utiliser et faire fonctionner son bon sens. Par exemple, le jour de l'Aïd, je vais taper à leur porte, manger chez eux...» 
(Hofstede, 1980, 2001; d'Iribarne, 1989) comme étant partagées à un plan national montre une contingence de ces valeurs aux situations locales de travail. Si l'on retrouve des constantes culturelles d'une entreprise à l'autre, notamment la solidarité entre ouvriers, la tendance au respect de la hiérarchie et à la soumission à l'autorité, en revanche, des aspects comme la discipline ou le sens du devoir dans le travail varient selon les contextes. Les facteurs discriminants trouvés sont relatifs à :

- une contrainte technologique (travail à la chaîne, travail peu valorisant, caractère interchangeable de l'ouvrier), liée à la pression du rendement qui s'accentue, notamment dans un secteur en crise comme celui de la confection;

- la faible qualification de la main-d'œuvre et la précarité de l'emploi qui contribuent à instaurer un rapport de force déséquilibré et déterminent le comportement des ouvriers;

- des contingences sectorielles, comme l'intensité de la concurrence et/ou le degré de crise économique dans le secteur.

En ce qui concerne les responsables hiérarchiques rencontrés, l'attitude d'autoritarisme, bien qu'elle soit plus largement répandue, ne serait pas uniquement déterminée par une culture nationale et se trouve en tous cas favorisée par la conjugaison des facteurs mentionnés ci-dessus. La dimension «culture individuelle» du responsable hiérarchique est par ailleurs un facteur plus subjectif et que nous n'avons pas évalué précisément, mais qui est visiblement à l'origine d'attitudes contrastées dans des contextes comparables.

\section{Perceptions culturelles et pratiques managériales}

L'incidence de la culture a également été analysée à travers les perceptions des capacités au travail et notamment la capacité à prendre des initiatives, les attitudes par rapport aux contraintes de qualité ou de rendement. Ces représentations ont ensuite été mises en relation avec des attitudes managériales comme celles de la confiance accordée, ou encore les caractéristiques des relations hiérarchiques et de pouvoir.

\subsection{Le cercle vicieux du paternalisme: une «culture du bon sens» limitée par la «peur de se tromper»}

Environ 60 \% des répondants pensent que les ouvriers ne sont plutôt pas capables, voire pas du tout capables, de prendre des initiatives. Les quelques prises d'initiatives relevées sont centrées autour de la prise en charge par l'ouvrier d'aspects mécaniques liés au poste de travail. 
Des aspects culturels sont avancés pour expliquer le manque d'initiative et, notamment, pour une majorité de responsables, le mode d'éducation qui est perçu comme produisant de la «passivité». Par exemple, un dirigeant dans l'agroalimentaire constate qu' «il n'y a pas d'initiative. Ils peuvent rester un jour à attendre si on ne leur dit pas quoi faire. Les ouvriers ont peur de se tromper, ce n'est pas pardonné au Maroc. Donc, ils ne prennent pas d'initiative. C'est un problème dû à la formation de base et au système d'apprentissage. La délégation est difficile à cause de ça: on passe $90 \%$ du temps à gérer des choses dont la valeur ajoutée est faible». Dans le même sens, un responsable de production dans la confection note que «c'est dû à la passivité de l'éducation qui se base sur "tais-toi, que sais-tu toi, tu ne sais rien..."; l'ouvrier a appris à ne pas prendre d'initiative. C'est une société passive.»

Cette éducation, défaillante aux yeux des interviewés, serait à l'origine d'un manque de confiance en soi souvent perçu et décrit, et accentué par le faible niveau de qualification de la main-d'œuvre en général.

Pour une majorité de responsables hiérarchiques, ces perceptions renforcent les tendances à la centralisation, au contrôle, à l'absence de délégation... développant en retour la faible aptitude de la main-d'œuvre à la prise d'initiatives ${ }^{28}$. Ce cercle vicieux du paternalisme devient un mode implicite de contrôle, notamment dans certaines PME familiales qui ne savent pas ou ne prennent pas le temps de faire autrement.

La prise de conscience de ces lacunes conduit toutefois certains dirigeants, rares il est vrai, à rechercher une mise en confiance par des comportements comme la valorisation verbale, l'écoute, et l'éducation/formation développée en interne pour pallier les insuffisances constatées sur le marché de l'emploi, même si la démarche n'est pas toujours aisée. Certains reconnaissent que les ouvriers ont «une culture du bon sens [...], certains points de vue très mûrs et objectifs » (DG dans la métallurgie), ou encore qu' «il faut le valoriser [l'ouvrier]. Quand c'est bien, il faut dire que c'est lui. Si c'est pas bien, il faut dire que c'est moi le responsable. Si on lui donne la possibilité, il trouve la solution. Il faut lui donner confiance» (responsable de production dans l'électroménager).

28. Comme le reconnaît finalement la gérante d'une petite entreprise de confection, «ils ne prennent pas d'initiative, mais c'est notre faute, on est toujours là pour tout suivre». 


\subsection{Les attitudes par rapport aux contraintes au travail : une différenciation en «eux» et «nous»}

Les discours des responsables interviewés quant aux attitudes relatives aux exigences de qualité et de rendement sur le poste de travail insistent sur des divergences entre le comportement des cadres et celui des ouvriers.

Le vocabulaire utilisé à ce propos témoigne de la difficulté à «faire de qualité»: «La qualité, c'est une construction, un combat quotidien» (DG dans la métallurgie); «C'est une lutte à maintenir» (responsable de production, industrie mécanique), « un casse-tête chinois pour le chef de chantier» (BTP); les explications avancées relèvent d'un référentiel contextuel et, dans une moindre mesure, culturel. Les facteurs contextuels ont trait à des « repères », des «environnements» différents, qui induiraient des niveaux d'exigence divergents entre cadres et main-d'œuvre, liés notamment aux niveaux de vie. Les raisons culturelles avancées sont, ici également, liées à l'éducation: il s'agit de la peur de se tromper et d'être pris en défaut, déjà relevée précédemment et induisant, par exemple, des pratiques de dissimulation des défauts de qualité de la part de la main-d'œuvre.

De même et notamment dans le secteur de la confection, les propos font souvent état du manque de formation de la main-d'œuvre comme facteur explicatif à un rendement qui ne répond pas aux attentes de l'entreprise.

Par rapport à la qualité, les réponses de l'encadrement sont variées. Certaines misent sur le facteur communication et s'appliquent à des efforts pédagogiques (schémas, photographies...). Mais pour une majorité, la qualité devient une contrainte imposée: «Il sait que le manque de qualité a comme conséquence une sanction» (responsable de production, confection). Les variables sectorielle, structurelle (taille d'entreprise) et de marché interviennent ici: dans les secteurs où la compétitivité par les coûts est fondamentale, la qualité est assimilée à un contrôle-produit et fait rarement l'objet de formations ciblées sur la main-d'œuvre, et ce, d'autant plus que l'entreprise est de petite taille. Par ailleurs, les discours adressés à la main-d'œuvre à l'occasion des démarches qualité sont influencés par le secteur et le marché: lors d'une autre enquête (Benabdeljlil, 2004), nous avions déjà relevé qu'ils évoquaient souvent les «dangers» présentés par l'environnement, la mondialisation, la concurrence.

En ce qui concerne les pratiques de contrôle du rendement au travail, elles évoluent avec la taille de l'entreprise: d'une surveillance directe par la présence physique et un suivi rapproché du travail, on passe à un système plus complexe basé par exemple sur l'octroi sélectif de primes au rendement. Dans les entreprises de plus grande taille, le contrôle se dépersonnalise, mais l'on note parallèlement moins de tolérance que chez les autres envers des 
contraintes relevant de la vie privée des salariés et qui pourraient perturber la production, alors que ce type de contrainte est davantage pris en considération et le «flou» mieux toléré dans les petites entreprises familiales.

\subsection{De la confiance déclarée au contrôle affiché: une double contrainte ou la nécessité de respecter l'amour-propre de la main-d'œuvre}

Les opinions formulées sur la possibilité de faire confiance aux ouvriers sont plutôt positives pour plus de $70 \%$ des personnes interrogées. Cependant, l'analyse des discours tenus, indiquant un décalage entre la perception et la pratique, amène à nuancer ce premier constat ${ }^{29}$.

Comme il fallait s'y attendre, la perception de la possibilité de faire confiance est liée à des représentations positives des valeurs précédentes (sens du devoir, respect de la hiérarchie, sens de la discipline) et les facteurs explicatifs relèvent plus d'une question d'individualité ou de culture personnelle, qui pousse le manager à pratiquer un management de proximité.

Les propos recueillis révèlent toutefois que l'attitude «confiance» et la pratique du contrôle, qui devraient être inversement corrélés chez les responsables, sont apparemment deux choses indépendantes, puisque même chez ceux qui déclarent qu'il est possible de faire confiance, le besoin de contrôler ou de surveiller est fréquemment évoqué.

Les responsables disent contrôler non pas tant parce qu'ils n'ont pas confiance que parce qu'ils ne peuvent déléguer. Le groupe d'entreprises analysées n'a pas permis de montrer, faute d'autres contextes de comparaison, si cette difficulté à déléguer est, en soi, un comportement culturel des managers marocains. Elle a cependant été également notée par les responsables étrangers interviewés et serait dans ce sens plutôt liée à des caractéristiques relatives à la main-d'œuvre (niveau de formation et type d'éducation). Ce qui paraît en revanche relever du culturel est la manière dont le contrôle s'exerce, notamment en ce qui concerne la qualité du travail.

En effet, bien qu'il soit généralement standardisé et accepté par la main-d'œuvre, ce contrôle pose problème lorsqu'il s'agit de faire passer un message de remise en question de la manière de travailler : «il faut contrôler mais de manière intelligente», déclare un dirigeant dans l'agroalimentaire,

29. Les pratiques montrent souvent un déficit de confiance par rapport à l'honnêteté, notamment dans le secteur de la confection où la pratique de la fouille des ouvriers à la sortie de l'usine est très répandue, mais aussi dans d'autres secteurs. 
«justifier par rapport à des aspects externes, à la concurrence... La confiance est un élément fondamental. Il ne faut pas montrer le contrôle, faire confiance et contrôler après ».

Dans plusieurs des entreprises de l'échantillon, on essaie de préserver les susceptibilités, le besoin de dignité, un amour-propre perçu: «La critique est peu acceptée. Les gens n'aiment pas être pris en défaut, ça les met très mal à l'aise » (responsable de production étranger); «Le Marocain est quelqu'un de coléreux, comme le Méditerranéen. Un expatrié va accepter la critique, le Marocain, non. Il y a un amour propre » (responsable de production marocain dans une entreprise étrangère de confection).

L'amour-propre est peut-être à l'origine de comportements d'ouvriers qui s'avèrent irritants pour leurs encadrants («Ils ne sont jamais responsables, on n'arrive jamais à savoir ce qui s'est passé» dit un responsable de production français ; «je n'ai jamais trouvé quelqu'un qui dit “j'ai fait une erreur”. On ne peut jamais savoir d'où vient l'erreur»), mais peut in fine devenir un levier pour satisfaire des contraintes de qualité, celles-ci devenant respectées non pas tant par «sens du devoir», que par crainte d'être «pris en défaut».

\subsection{L'affectivité dans les relations de travail, entre profil culturel des employés et opportunisme de l'encadrement}

La plupart des responsables rencontrés reconnaissent que les aspects affectifs jouent «beaucoup» dans les rapports qu'ils ont avec les ouvriers. L'attente des employés à ce niveau, qui relève vraisemblablement d'un profil culturel, se traduit par des sollicitations dont les responsables font l'objet, auxquelles ils s'adaptent plus ou moins consciemment et qui amènent à personnaliser la relation de travail.

Une majorité sont partie prenante dans ce jeu affectif avec la maind'œuvre et répondent à des attentes qui dépassent le cadre du travail: conseils pour l'achat de logements, pour les taux des crédits, résolution de démarches administratives, problèmes de scolarisation des enfants... les sollicitations sont nombreuses. Un responsable de production dans l'industrie mécanique raconte ainsi: «il m'arrive d'être dans les confidences des gens. Ils me racontent leurs problèmes... J'essaie de les aider dans leur réflexion: il m'est arrivé même d'entraider des gens proches du divorce [...] pour qu'il n'y ait plus de tension».

Ces attentes reflètent la vulnérabilité de la main-d'œuvre face à un environnement socioéconomique qui leur paraît peu lisible ou difficile, mais sont également d'ordre culturel au sens où l'on note une sorte de transposition de relations de type familial au sein de l'entreprise, qui est notamment 
exprimée dans le vocabulaire utilisé lors des entretiens: «Je fais l'assistante sociale»; «la grande sœur» déclarent des responsables d'atelier dans la confection. «Ils sont comme nos enfants», constate le dirigeant d'une PME de confection.

Pour une majorité de responsables hiérarchiques, la personnalisation des relations paraît à la fois naturelle et relevant de leur rôle. En ce sens, elle correspondrait à un mode de management «culturel» qualifié dans d'autres études de paternaliste. L'aspect relationnel est aussi analysé par certains comme un moyen de compenser, sur le plan interne, des stimulants d'ordre économique et notamment salariaux, qui restent relativement faibles, et, sur le plan externe, un système institutionnel de sécurité sociale défaillant.

Ceux qui expriment cette perception mettent tous en œuvre des pratiques de proximité et de valorisation, verbales ou concrètes, avec pour objectif implicite de développer à la fois l'attachement et l'adhésion du personnel: «Il y a une reconnaissance sociale, morale, qui compense les conditions de vie difficiles et qui fait partie de la rémunération [...] Les Marocains sont avides de relations », explique, par exemple, un dirigeant. Les réponses aux sollicitations de la main-d'œuvre deviennent, pour ces managers, un levier implicite pour susciter l'adhésion du personnel ${ }^{30}$ : «Ça facilite la communication, surtout pour atteindre le rendement, la qualité et la confiance.» «Au Maroc, il suffit de passer ta main dans son dos, il fait le maximum: on travaille ce côté système associatif. L'ouvrier adhère surtout grâce à cet aspect proximité - relation» (agents de maîtrise).

Par ailleurs, l'importance que revêt la capacité d'écoute et d'anticipation du responsable par rapport à des problèmes sociaux que pourrait vivre la maind'œuvre, avec le risque d'impact sur le travail qu'ils impliquent, est souvent soulignée : «il ne faut pas que ses problèmes privés aient un impact sur la productivité» (dirigeant dans l'agroalimentaire). «On essaie de garder de bonnes relations, d'éviter les rancunes pour qu'ils ne se vengent pas, par exemple en mettant des substances toxiques» (gérante dans l'agroalimentaire).

De fait, dans ces entreprises où les discours mettent en avant le côté «esprit de famille», l'attachement de la main-d'œuvre est en général estimé positivement.

Cependant, l'affectif n'implique pas le «copinage»: il faut maintenir un minimum de distance dans les relations, garder l'auréole du «chef», le bon dosage entre paternalisme et autorité, certains insistant particulièrement

30. Un DG français a également déclaré faire plus souvent le tour de l'usine au Maroc qu'il ne le faisait en France, parce que «ça fait vraiment plaisir aux gens» de voir le directeur. 
sur l'importance de cette dernière : «il faut beaucoup d'autorité. Vu le milieu [des ouvrières], c'est difficile d'être copine. Être gentille, c'est être faible», constate cette responsable d'atelier dans la confection; il faut «un peu de respect, un peu de peur, un peu d'affection », continue-t-elle, résumant ainsi les ingrédients nécessaires à un bon style de commandement. «Je dois tout savoir d'elles, mais elles ne doivent rien savoir de moi», précise une autre responsable d'atelier dans une PME du même secteur, expliquant comment elle assoie son autorité.

Le rôle de la maîtrise est essentiel par rapport à ce besoin «d'écoute permanente», notamment dans les entreprises dont une taille plus grande éloigne les dirigeants de la main-d'œuvre: les agents de maîtrise interviewés se disent, dans l'ensemble, attentifs aux non-dits et aux signes d'insatisfaction qui peuvent se manifester et mettent l'accent sur la double compétence, technique et humaine, qu'implique leur position.

\subsection{Les entreprises «atypiques»: des relations professionnelles seulement}

Certains responsables hiérarchiques, par contre, résistent à entrer dans ce jeu. C'est notamment le cas de certains cadres étrangers interviewés, mais aussi de cadres marocains. Pour ces quelques cas qui sortent de la tendance générale, il est difficile de savoir, vu la taille de l'échantillon, dans quelle mesure il s'agit de caractéristiques liées à l'entreprise (comme sa nationalité) ou simplement d'attitudes individuelles. Dans les deux entreprises de confection étrangères de l'échantillon, toutefois, l'aspect paternaliste disparaît ou, tout au moins, «descend» dans la pyramide hiérarchique: tel agent de maîtrise (Marocain) avoue que les aspects affectifs sont importants, «mais d'une façon informelle et même parfois discrètement parce que le directeur est un Espagnol et il est sévère, trop professionnel».

La place occupée par les aspects affectifs paraît ainsi diminuer avec le degré de formalisation du système managérial qui, dans certaines entreprises, «professionnalise» les relations et rigidifie les rapports humains. Dans ces cas, contrairement aux précédents, le degré d'attachement de la main-d'œuvre à l'entreprise est estimé comme étant «faible» par les responsables interviewés et se fait d'abord sur les aspects matériels, les conditions de travail. Les pratiques de proximité perdurent toutefois, mais sont relayées par le niveau de la maîtrise, ce qui semble indiquer une constante dans le besoin de relations hiérarchiques personnalisées au niveau de la main-d'œuvre. 


\section{Conclusion}

Cette enquête sur le rôle des facteurs culturels dans les modes de management des entreprises marocaines a conforté notre paradigme de départ, au sens où les résultats montrent que la «matérialité des situations de travail» (Friedberg, 2005) est le résultat complexe de la conjugaison de plusieurs facteurs: mis à part des valeurs et attitudes liées aux cultures sociétales, d'autres variables contextuelles, qui conditionnent en particulier le degré de précarité des situations de travail, sont à prendre en considération pour une compréhension plus fine des attitudes et du jeu des relations humaines.

Les constantes culturelles identifiées, et qui pourraient être interprétées selon la grille de lecture de Hofstede, sont relatives notamment à un investissement affectif dans les relations hiérarchiques et à une sollicitation pour une personnalisation de ces relations; à une tendance au respect de la hiérarchie, voire à la soumission à l'autorité ; à un amour-propre de la main-d'œuvre au travail; et à un sens élevé de la solidarité entre ouvriers.

Les variables contextuelles mises en évidence ne peuvent être ignorées, car elles jouent dans le sens d'un renforcement ou, au contraire, d'un affaiblissement de certaines tendances culturelles. Par exemple, des attitudes pouvant être interprétées comme étant liées à une culture paternaliste dominante, à la soumission à l'autorité prônée par le mode d'éducation prévalent dans la société marocaine, sont renforcées par le faible niveau de qualification, voire l'analphabétisme, de la main-d'œuvre marocaine, ou encore par la situation structurelle de crise au niveau du marché de l'emploi. Ces contraintes engendrent chez les ouvriers des comportements rationnels (au sens de Crozier) avant d'être culturels. Le sens de la solidarité, valeur culturelle, est également renforcé par un système institutionnel de protection sociale défaillant...

Pour une meilleure compréhension du contexte étudié, l'enquête a montré comment la culture peut être intégrée au management au Maroc: les valeurs culturelles telles qu'elles sont perçues par les personnes enquêtées sont utilisées comme un levier par certains d'entre eux, consciemment ou non. Elles peuvent donner lieu à des comportements opportunistes de leur part, par exemple, sur le plan de la personnalisation des relations de travail. Elles guident certaines conduites, comme lorsqu'il s'agit de s'ajuster à un amour-propre perçu. Cependant, là également, interviennent des facteurs contextuels, qui peuvent renforcer les comportements culturels (tendance au paternalisme, par exemple), mais aussi conduire à les dépasser, une autre variable explicative étant celle de la culture individuelle du manager.

Pour la pratique managériale, une lecture par des caractéristiques sectorielles (intensité de la concurrence, pression du rendement), par les 
niveaux de formation de la main-d'œuvre, par le degré de précarité sociale, peuvent permettre de mieux comprendre des comportements qui paraissent en premier lieu d'abord culturels et aider à les gérer ou à les anticiper.

Par rapport à des problématiques de recherche s'inscrivant dans le cadre du «management interculturel », il est donc important de relativiser la place des cultures sociétales dans la détermination des comportements: dans l'entreprise, les manifestations de valeurs culturelles ne sont pas absolues, mais contingentes aux situations locales et aux relations complexes qu'entretiennent les membres de l'entreprise avec leur environnement, à la fois culturel, social et économique. Une entrée par les cultures sociétales seules risque finalement d'appauvrir la compréhension des contextes locaux de management et des attitudes au travail.

\section{Bibliographie}

Abraham, J. (1992), Culture d'entreprise: essai de formalisation et relations avec la performance, Thèse de doctorat en sciences de gestion, IAE de Poitiers.

Ali, A.J.et R. WAHABi (1995), «Managerial systems values in Morocco », International Studies of Management and Organization, vol. 25, n 3 , automne.

BenabdelJuil, N. (2004), «Démarche qualité et changement organisationnel dans les PME marocaines », Critique économique, Rabat, n 13, été, p. 159-172.

Bourrier, M. (2005), «L'analyse culturelle: un horizon, pas un point de départ. En réponse à Philippe d'Iribarne», Revue française de sociologie, vol. $46, \mathrm{n}^{\circ} 1$, p. 171-176.

Cuche, D. (2004), La notion de culture dans les sciences sociales, $3^{e}$ éd., Paris, La Découverte, coll. «Repères».

DAYAn, A. (dir.) (1999), «La culture organisationnelle», dans Manuel de gestion, p. 111-120, vol. 1, livre 1, partie 2, IV, Paris, Ellipses / AUF.

ECKHARDt, G. (2002), «Review: "Culture's consequences [...]” by Geert Hofstede, 2001 », Australian Journal of Management, vol. 27, n 1, juin, p. 89-94.

El Amrani, J. et M.A. Chebini (2003), «Culture et management au Maroc», Repères et perspectives, Rabat, $\mathrm{n}^{\circ}$ 4, hiver, p. 87-107.

El Aoufi, N., A. Akesbi, N. Benabdelulil, A. Debbagh, M. Lahlou et M. Zouiten (2000), L'entreprise côté usine: les configurations sociales de l'entreprise marocaine, Édition du Groupe d'études et de recherches sur les ressources humaines et l'entreprise, Rabat.

Flowers, V., C. Hughes, M. Myers et S. Myers (1975), Managerial Values for Working: An AMA Survey Report, New York, American Management Association.

FriedBerg, E. (2005), «La culture "nationale" n'est pas le tout social. Réponse à Philippe d'Iribarne», Revue française de sociologie, vol. 46, n 1, p. 177-193. 
Geertz, C. (1992), Observer l'islam. Changements religieux au Maroc et en Indonésie, Paris, La Découverte.

Graves, C. (1970), «Level of existence: an open system theory of values», Journal of Humanistic Psychology, vol. 10, n 2, p. 131-154.

Hall, E.T. (1984), Danse de la vie. Temps culturel, temps vécu, Paris, Seuil.

Hofstede, G. (1980), Culture's Consequences: International Differences in WorkRelated Values, Beverly Hill, Cal., Sage Publications.

Hofstede, G. (1994), Vivre dans un monde multiculturel, Paris, Éditions d'Organisation.

Hofstede, G. (2001), Culture's Consequences: Comparing Values, Behaviours, Institutions and Organizations Across Nations, $2^{\mathrm{e}}$ éd., Thousand Oaks, Cal., Sage Publications.

IRIBARNE (d'), P. (1989), La logique de l'honneur: gestion des entreprises et traditions nationales, Paris, Seuil.

IrIBARNe (d'), P. (2005), «Analyse stratégique et culture: un nécessaire retour aux sources », Revue française de sociologie, vol. 46, n 1, p. 151-170.

Lachman, R., A. Nedd et B. Hinings (1994), «Analysing cross-national management and organizations: a theoretical framework», Management Science, vol. 40, $\mathrm{n}^{\circ} 1$, janvier, p. 40-55.

Larcher, Y. (2003), Démocratie, modernité et culture marocaine: l'apparition d'identités en transition?, Mémoire de DEA de sociologie, Université de Toulousele-Mirail.

LESCA, N. et A. BARTEL-RADiC (2001), «Résultats, limites et perspectives de recherche en management interculturel: quelques apports de la théorie des représentations», dans $\mathrm{X}^{\mathrm{e}}$ conférence de l'Association internationale de management stratégique, juin.

Lотн, D. (2006), Le management interculturel, Paris, l'Harmattan, coll. «Entreprises et management».

Maurice, M. (1992), «Les sociologues et l'entreprise», dans R. Sainsaulieu (dir.), L'entreprise: une affaire de société, chapitre 13, p. 303-331, Paris, Presses de la Fondation nationale des sciences politiques, $353 \mathrm{p}$.

Mezouar, A. (dir.) (2002), L'entreprise marocaine et la modernité. Recherche sur les conditions de changement culturel pour un progrès durable, Casablanca, Centre d'études et de recherches des dirigeants.

Michelat, G. (1975), «Sur l'utilisation de l'entretien non directif en sociologie », Revue française de sociologie, vol. $16, \mathrm{n}^{\circ} 2$.

Miles, M.B. et A.M. Huberman (1991), Analyse des données qualitatives. Recueil de nouvelles méthodes, Bruxelles, De Boeck Université.

Sainsaulieu, R. (1987), Sociologie de l'organisation et de l'entreprise, Paris, Presses de la Fondation nationale des sciences politiques et Dalloz, coll. «Amphithéâtre», $390 \mathrm{p}$.

Revue internationale P.M.E., vol. 20, nº 2, 2007 
Sainsaulieu, R. (dir.) (1992), L'entreprise: un affaire de société, Paris, Presses de la Fondation nationale des sciences politiques, $353 \mathrm{p}$.

SCHEIN, E.H (1984), «Coming to a new awareness of organizational culture », Sloan Management Review, hiver.

Tisserand, P. (2001), «Culture et travail: du local au mondial», dans les Actes $d u$ VIII $^{e}$ Congrès international de l'Association pour la recherche inter-culturelle (ARIC), Université de Genève, septembre.

Trompenaars, F. et C. Hampden-Turner (1993), L'entreprise multiculturelle, Paris, Maxima.

ZGHAL, R. (1994), La culture de la dignité et le flou de l'organisation. Culture et comportement organisationnel: schéma théorique et application au cas tunisien, Tunis, Édition du Centre d'études, de recherches et de publications. 